\title{
Gastro-intestinal Digestibility of Processed Forms of Cow's Milk Proteins under Simulated Infant and Adult Conditions Characterised by in vitro Methods
}

\author{
Cheryl Taylor ${ }^{1}$, Thomas Nebl ${ }^{2} \&$ Louise E. Bennett ${ }^{1}$ \\ ${ }^{1}$ CSIRO Agriculture and Food, 671 Sneydes Road, Werribee, Victoria, 3030, Australia \\ ${ }^{2}$ CSIRO Manufacturing, 343 Royal Parade, Parkville, 3052, Australia \\ Correspondence: Professor Louise Bennett, Department of Chemistry, Monash University, Wellington Road, \\ Clayton, 3800, Australia. Tel: 61-399-056-136. E-mail: louise.bennett1@ monash.edu
}

Received: October 26, 2018

Accepted: November 23, $2018 \quad$ Online Published: January 17, 2018

doi:10.5539/jfr.v8n1p80

URL: https://doi.org/10.5539/jfr.v8n1p80

\begin{abstract}
Human digestion involves chemical, biochemical and fermentative processes integrated to achieve optimal nutrient absorption along the gastro-intestinal (GI) tract. In particular, efficient gastro-intestinal enzymatic digestion of proteins is critical for maximum upper intestinal protein absorption and may influence the distribution of dietary protein between the 'host' and microbiota. However, the relative efficiency of infant versus adult conditions of GI digestion of cow's milk products have not been systematically studied. Conditions for in vitro GI enzymatic digestion, optimised for either infant or adult conditions, were applied to test pasteurised, skimmed milk, skimmed milk powder (SMP) and whey and casein protein fractions of cow's milk. Research methods included digestion monitoring by $o$-phthaldialdehyde (OPA) derivitisation of peptides and free amino acids, and digestate analysis to characterise low mass 'absorbing' products (size exclusion chromatography) and larger non-absorbing products (700-3500 Da) by MALDI-TOF-MS. The results demonstrated significantly lower digestion efficiency for infant versus adult digestion conditions, particularly in the gastric phase. Digestibility of pasteurised milk and SMP were generally lower than either whey or casein protein fractions. Lower overall protein digestibility was associated with lower and higher proportions of 'absorbing' and 'non-absorbing' peptides, respectively. The higher yield of 'non-absorbing' peptides for infant digestion may permit strategic release of peptides with receptor-antagonistic bioactivity along the gut, and/or may promote supply of nitrogen for the microbiota. The favouring of digestion-resistant peptides to the colon due to processing requires further research to also investigate potential negative relationships with health.
\end{abstract}

Keywords: in vitro digestion, pancreatin, pepsin, $o$-pthaldialdehyde, molecular size, protein aggregation, free amino acid

Abbreviations: WPI: whey protein isolate; SMP: skimmed milk powder; MALDI-TOF-MS: matrix-assisted laser desorption ionization time-of-flight mass spectrometry; SEC: size-exclusion chromatography

\section{Introduction}

Milk represents the exclusive source of nutrients for the neonate and in this context, is 'designed' for adequate nourishment of the host per se and also for colonisation of a functional intestinal microbiota. Human babies are reared ideally on breast milk but in some circumstances, on formula prepared from cow or goat milk (Zhou et al., 2014) and other non-animal protein sources (Hozyasz \& Slowik, 2013). Thermal processing of formula is necessary for microbiological safety and the effects on supply of protein nutrition appear to be acceptable. In contrast, adults can consume a very broad range of dairy products, and unlike babies, are not reliant on these products as an exclusive source of protein. Instead, dairy products are recommended in the adult human diet to provide rich sources of macro- and micro-nutrients. In addition, several categories of dairy product consumed beyond infancy such as yoghurt and cheese have undergone some degree of fermentative hydrolysis that can promote protein digestibility and release potentially bioactive peptides (Hernandez-Ledesma, Garcia-Nebot, Fernandez-Tome, Amigo, \& Recio, 2014). In other words, the consumption of milk by infant and non-infant consumers has different purposes and outcomes for health, but the suitability of processed forms of milk for respective purposes is not well understood. 
Human digestion comprises acid/enzyme, enzymatic and fermentative stages, in the stomach, upper and lower intestines, respectively. Sequence specificities for action of pepsin in the stomach are amide linkages connecting hydrophobic, aromatic amino acids: phenalalanine, tyrosine and tryptophan. In the upper intestine, chymotrypsin also targets aromatic amino acids, leucines and methionine while trypsin cleaves amide linkages at the carboxyl side of arginine and lysine but is inhibited by adjacent prolines (Lindberg, Borulf, \& Jakobsson, 1989). Pepsin, chymotrypsin and trypsin are endo-peptidases cleaving within the polypeptide chain while brush-border enzymes are exo- and endo-peptidases that drive final stages of hydrolysis into short peptides and amino acids (Picariello et al., 2015) for absorption in the upper gut (Fan et al., 2015; Ten Have, Engelen, Lulking, \& Deutz, 2007). Thermal processing of milk that induces Maillard reactivity between proteins and lactose targets primary amines, particularly at arginines and lysines, with potential adverse effects on lysine bioavailability (Rudloff \& Lonnerdal, 1992), while thermal denaturation of proteins accelerates thiol-disulfide protein-protein cross-linking and physical aggregation (Wijayanti, Bansal, \& Deeth, 2014; Williams, D'Ath, \& Zisu, 2008) that may, to some extent, promote digestibility and bioavailability.

Absorption of small peptides and amino acids from dietary sources is intended to occur primarily in the upper intestine where supply of these species into the circulation via the portal vein and liver is regulated by luminal transport at the brush border membrane (BBM, Ten Have et al., 2007). Luminal transport of digested proteins depends on the amino acid 'quality' profile with lesser quality proteins enriched in non-essential amino acids (NEAA) retained longer in the lumen. As such, digestates more slowly released into the circulation maximise opportunity for amino acid absorption (Ten Have et al., 2007). Turnover of total $\mathrm{N}$ is balanced between dietary inputs and faecal outputs with very dynamic pathways of protein synthesis by anabolic metabolism (systemic) and also proliferating bacteria (intestinal), utilising proteins, peptides, amino acids and ammonia (Davila et al., 2013). Under normal conditions, nitrogenous products of bacteria in the colon are utilised by the bacteria per se and may not be significantly available for the host (Davila et al., 2013). However, 'excess' dietary N circulating as urea is available for colonic reabsorption and bacterial utilisation, representing a pathway for $\mathrm{N}$ interchange between the host and colonic microbiota (Davila et al., 2013; Fuller, 2012).

The proportions of dietary $\mathrm{N}$ supply to the host versus microbiota depends on the balance of dietary intake with need and is perturbed in nutrient oversupply (obesity), fasting and critical illness (Morowitz, Carlisle, \& Alverdy, 2011) and, it is hypothesized, also by thermal processing. In support, relationships of processing with amino acid bioavailability and post-prandial protein synthesis in adults have revealed apparently superior absorption but lower anabolic retention of skimmed UHT versus microfiltered (unpasteurised) and pasteurised milk proteins, which correlated with higher levels of serum and urine urea (Lacroix et al., 2008). This effect was attributed to the enhanced rate of digestion of UHT milk following process-mediated dispersion of casein micelles, and demonstrated that processing is likely to differentially affect the distribution of milk proteins between absorption and ileal 'loss' to the colon. Apart from compromising protein digestibility, severe thermal processing of milk also lowers absorption and retention of calcium (Seiquer, Delgado-Andrade, Haro, \& Navarro, 2010), also supporting that processing can divert bound micro-nutrients from optimal absorption pathways.

In this study, in vitro methods for simulated gastro-intestinal digestion modelling infant and adult conditions were validated and applied to a selection of processed milk products including: pasteurised skimmed milk, skimmed milk powder, whey and casein protein proteins. Methods included monitoring of progressive digestion by derivatisation of hydrolysates with $o$-phthaldialdehyde (OPA) and characterising size distribution of digestates by matrix-assisted laser desorption ionisation mass spectrometry (MALDI-MS) and size exclusion chromatography. Based on size distributions of digestion-resistant fractions, the results were interpreted to reflect differences in potential for intestinal absorption versus colonic fermentation, as a function of infant or adult digestion conditions and type of milk product.

\section{Materials and Methods}

\subsection{Materials}

Commercial pasteurised skimmed milk (PhysiCal) was from Pauls, South Brisbane, Australia. High heat-treated skimmed milk powder was from Tatura Milk Industries Ltd (Victoria, Australia). Acid whey protein isolate (79\% total protein, Natropro) was from Murray Goulburn Co-operative Co. Ltd (Victoria, Australia), and sodium caseinate (93\% total protein) was from Fonterra Co-operative Group Ltd, (Auckland, New Zealand). Pepsin (453 $\mathrm{U} / \mathrm{mg}$ solids), pancreatin (8xUSP), o-phthaldialdehyde (OPA), serine, sodium dodecyl sulphate (SDS), dithiothreitol (DTT) and buffer salts were obtained from Sigma Chemical Co. (St Louis, MO, USA).

\subsection{Nitrogen Analysis}

After freeze-drying liquid samples, total nitrogen content of all dried milk products were determined using a 
LECO Trumac ${ }^{\circledR} \mathrm{N}$ analyser (LECO Corporation, Michigan, USA) from which total protein contents were estimated using the conversion factor of 6.38 (Maubois \& Lorient, 2016).

\subsection{Simulated Gastro-intestinal Digestion}

Simulated in vitro digestion was based on the method of Wu et al (Wu, Taylor, Nebl, Ng, \& Bennett, 2017) but omitting bile salts, and is briefly described. For simulated in vitro digestion under adult conditions, milk products were reconstituted in Simulated Gastric Buffer (SGB, $150 \mathrm{mM} \mathrm{NaCl}, \mathrm{pH} 2.5$ ) at $8.0 \mathrm{mg} / \mathrm{mL}$ total protein before mixing with pepsin $\left(50 \mathrm{mg} / \mathrm{mL}\right.$ in SGB) and commencing incubation at $37^{\circ} \mathrm{C}$ with gentle agitation in a rotary mixer. Gastric digestion progressed for $1 \mathrm{hr}$ before adjusting to $\mathrm{pH} 7.5$ and addition of pancreatin solution (10 $\mathrm{mg} / \mathrm{mL}$ in $25 \mathrm{mM}$ bis-Tris Propane, $\mathrm{pH}$ 7.5). Duodenal digestion was monitored for $3.5 \mathrm{hr}$. Two methods of enzyme inhibition were applied. For the method validation study with pasteurised skim milk, digest samples were immediately heated at $100^{\circ} \mathrm{C}$ for 5 min before cooling and subsequently diluted (1/200) and stored in 100 $\mathrm{mM}$ sodium bicarbonate, $\mathrm{pH} 7.5$ pending analysis by OPA assay. For the comparison of milk protein products, digest samples were mixed with an equal volume of $0.25 \mathrm{M} \mathrm{NaOH}$ and subsequently diluted (1/100) and stored in $100 \mathrm{mM}$ sodium bicarbonate, $\mathrm{pH} 7.5$ pending analysis by OPA assay.

For simulated in vitro digestion under infant conditions, samples were also treated at $8.0 \mathrm{mg} / \mathrm{mL}$ total protein, but with conditions adjusted to better simulate infant physiology based on previous reports (Bourlieu et al., 2014; Dupont, Mandalari, Molle, Jardin, Rolet-Repecaud, et al., 2010; Menard et al., 2014). Gastric digestion was conducted at a concentration of $15 \mathrm{mg} / \mathrm{mL}$ pepsin at $\mathrm{pH} 3.0$ and pancreatic digestion was conducted at a concentration of $5 \mathrm{mg} / \mathrm{mL}$ pancreatin at $\mathrm{pH}$ 6.5. All digestions were performed in at least duplicate and an enzyme-reagent control, matched to digestion conditions, was conducted with each set of digested samples.

\subsection{Monitoring Hydrolysis by OPA Assay}

Extent of protein hydrolysis was measured in the digestion sample series by derivitisation of peptides with $o$-phthaldialdehyde (OPA). Hydrolysate samples previously diluted in sodium bicarbonate buffer were further diluted (1/50) in OPA Assay Buffer (100 mM sodium borate, pH9.9, 0.1\% SDS, $50 \mu \mathrm{g} / \mathrm{mL}$ OPA, $50 \mu \mathrm{g} / \mathrm{mL}$ DTT) and loaded onto 96 well plates (Nunc, Thermo Scientific, Waltham, MA, USA) before sealing with adhesive film and incubating at $40^{\circ} \mathrm{C}$ for $15 \mathrm{~min}$. After cooling to room temperature, fluorescence was measured (excitation, $340 \mathrm{~nm}$; emission, $450 \mathrm{~nm}$ ) using a Varioskan Flash plate reader (Thermo Scientific, Waltham, MA, USA). Dilutions in respective buffers were optimised to ensure fluorescence intensity was within the linear response range observed for the standard, serine, from $0-250 \mu \mathrm{g} / \mathrm{mL}$.

\subsection{Analysis of Final Digests: Matrix-assisted Laser Desorption Ionisation Mass Spectrometry (MALDI-MS)}

Analysis of digestate peptide masses was conducted by matrix assisted laser desorption ionization-time of flight (MALDI-TOF) spectroscopy (UltrafleXtreme TOF-TOF spectrometer, Bruker, Bremen, Germany) after dilution in water (1/50, in duplicate), by the method described previously (Wu et al., 2017). Peptides in the M/Z mass range: 700-3500 Da were detected and data was processed, with peak detection set at a signal-to-noise ratio of 3 (Wu et al., 2017). MALDI-TOF peptide analysis results were evaluated as total unique peptide count $(\mathrm{N})$ and proportions of peptides in size ranges: $\mathrm{N}<1 \mathrm{kDa} ; 1<\mathrm{N}<2 \mathrm{kDa}$ and $>2 \mathrm{kDa}$. MALDI-TOF-MS analysis was conducted on duplicates of digestates and reported as mean and SEM.

\subsection{Data Analysis}

Differences between measures of digestion characteristics of milk products were analysed by ANOVA and multiple pairwise comparisons determined by Tukey's Test (Sigma Plot for Windows, version 13.0, Systat Software Inc., Chicago, IL, USA).

\section{Results}

\subsection{Comparison of Infant Versus Adult Conditions of Simulated Gastro-intestinal Digestion}

Pasteurised skimmed milk was subjected to in vitro gastro-intestinal digestion using both 'infant' and 'adult' digestion conditions and digestion was followed by OPA assay and MALDI-TOF-MS analysis (Figure 1). Sample preparation associated with the OPA assay (ie, heating in SDS) solubilised and likely detected all proteins, peptides and amino acids, whereas MALDI-TOF-MS analysis characterised the fraction of nominally 'non-absorbing' larger peptides. The larger polypeptide fraction of $>3500 \mathrm{Da}$ was undetected by MALDI-TOF-MS analysis, and therefore likely excluded unhydrolysed enzymes. Otherwise, hydrolysed milk proteins were expected to be digested into peptide and amino acid species $<3500 \mathrm{Da}$ and accounted for either in total by the OPA assay method or in the defined mass sub-fraction, by MALDI-TOF-MS. Under the experimental conditions of enzyme to substrate ratio for either infant or adult conditions, the extent of in vitro 
digestion reaches a plateau in the intestinal digestion phase (Figure 1a), suggesting exhaustion of recognition sites of proteins for the enzymes in the pancreatin preparation. This is also reflected in plateauing of measures of small peptides and FAAs (detected by SEC) and also in the detection of larger peptides (of size range 700-3500 Da detected by MALDI-TOF-MS). The limitation of the in vitro digestive model, which does not include brush border membrane enzymes, nor fermentation, to achieve 'complete' digestion, are discussed further in Section 4.1 .

In general, for both infant and adult conditions, digestion rate was limited under gastric conditions (up to $60 \mathrm{~min}$ ) and then accelerated under intestinal conditions from 60 to 270 min producing a sigmoidal-shaped hydrolysis curve (Figure 1a). Compared with infant digestion, the extent of digestion based on OPA assay, was approximately $40 \%$ higher under adult conditions (Figure 1a) and infant digestion of milk was very low in the gastric stage based on FAA release (Figure 1b). Compared with infant conditions, higher extent of digestion under adult conditions was accompanied by relatively higher levels of both FAAs and small peptides in the gastric phase (Figures 1b, 1c). In contrast, levels of small peptides were higher in the intestinal phase under infant versus adult conditions, suggesting that infant digestion produced a longer intestinal lifetime of larger peptides (Figures 1b, 1c), and inferring potential signalling or functional roles for these peptides.

The count of unique peptides detected by MALDI-TOF-MS was also higher for adult (Figure 2b) versus infant (Figure 2a) digestion. Under infant conditions, the count of peptides increased further under intestinal conditions (Figure 1b), whereas for adult conditions, the peptide count plateaued over time (Figure 1c). Compared with adult digestion, the lower overall count of peptides in the gastric phase correlated with a significantly lower yield of peptides in the 1-2 and <1 kDa ranges for infant digestion (Figure 2a), supporting a significantly delayed rate of gastric digestion. The relatively slower digestion under infant conditions and sustained presence of undigested larger proteins, likely reflect the lower ratio of enzyme to substrate and higher $\mathrm{pH}$ of infant gastric digestion conditions, inhibiting enzyme activity.

(a)

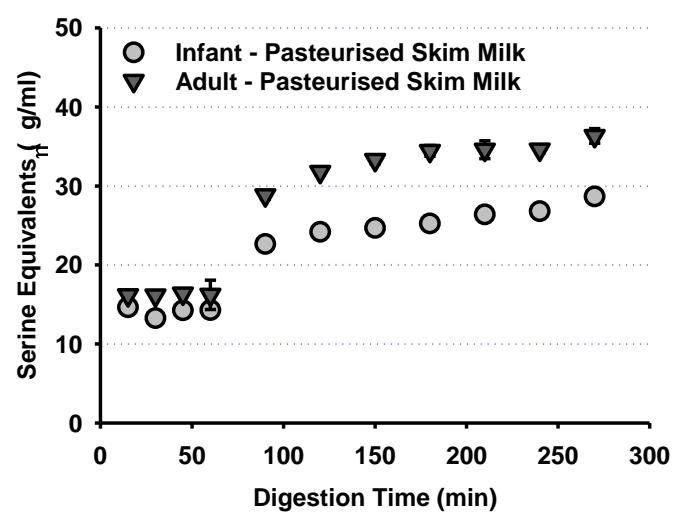

(b)

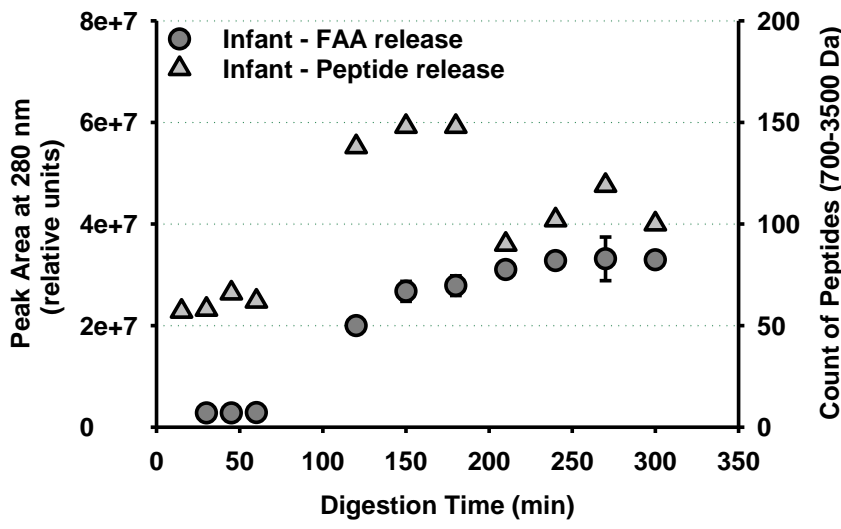

(c)

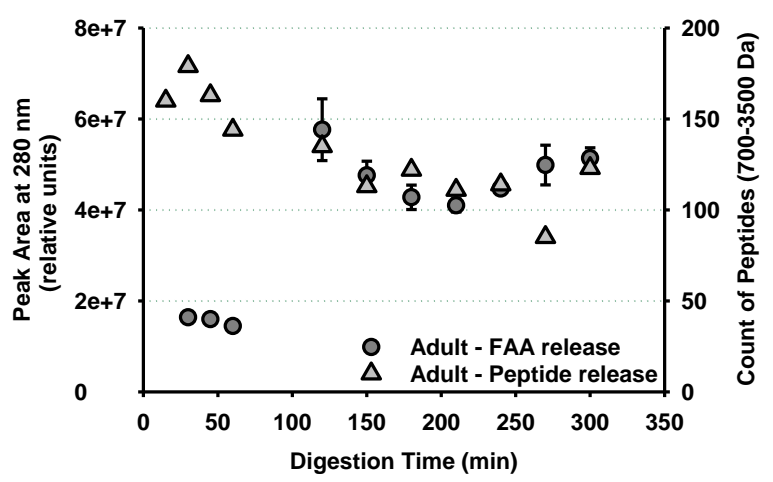

Figure 1. In vitro gastro-intestinal digestion profiles for pasteurised milk monitoring by (a) OPA assay (showing degree of hydrolysis), SEC chromatography (proportions of low mass free amino acids and peptides, FAA release, left axis) and MALDI-TOF-MS (count of unique, larger peptides in range 700-3500 Da, Peptide release, right axis) under (b) infant and (c) adult simulated digestion conditions. Digestions, SEC and MALDI-TOF-MS data represent the mean and standard error (SE) of duplicates and OPA analysis in quadruplicate 
(a)

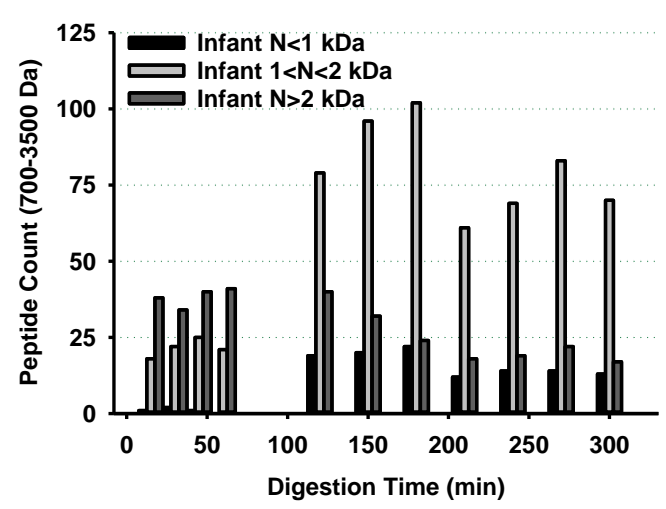

(b)

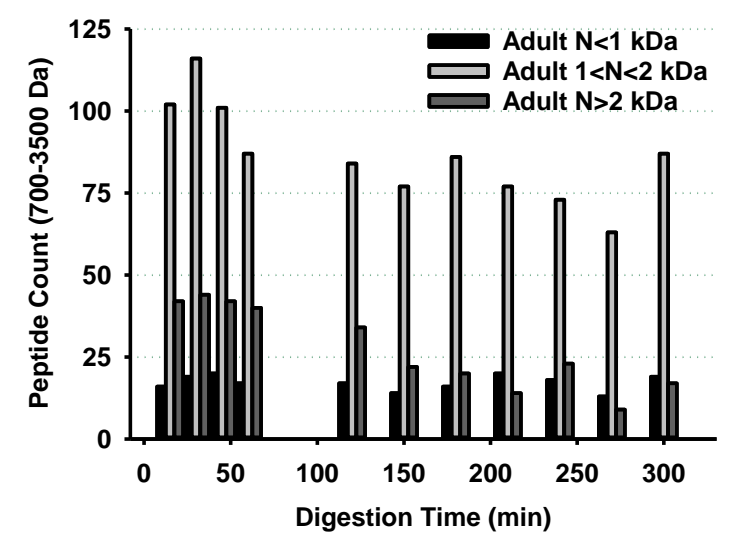

Figure 2. MALDI-TOF-MS analysis of in vitro digestion sample series showing the count of unique peptides in nominated size ranges following (a) infant or (b) adult simulated digestion conditions. Results exclude undigested proteins and enzymes $>3500 \mathrm{Da}$

\subsection{Comparing Gastro-intestinal Digestion of Selected Milk Protein Products}

Digestion properties of an independent set of milk products were then compared under infant (Figure 3a) and adult (Figure 3b) conditions. Based on digestion curve maxima, absolute extents of protein digestion were relatively delayed under infant versus adult conditions. However, relative extents of digestibility of respective milk products under infant versus adult conditions displayed similar relative trends (Figure 3c). Under either infant or adult simulated digestion conditions, involving careful standardisation of enzyme to protein ratio, digestibility of products decreased in the order: whey proteins $>$ caseins $\simeq$ pasteurised skim milk $>$ SMP (Figure $3 c$ ). The digestibility of SMP versus pasteurised skim milk was significantly lower under infant conditions but not significantly different under adult conditions, signifying the lower enzymatic digestion efficiency of infant gastro-intestinal conditions. The results support the frequently reported observation of more rapid and extensive digestibility of whey proteins versus caseins under both infant and adult conditions. Considering that the plateauing of digestion curves reflects exhaustion of protein recognition sites for pancreatin enzymes, differences in values of serine equivalents at 270 mins therefore also reflect differences in inherent digestibility of tested products due to processing.

Final digestates were also analysed by MALDI-TOF-MS, which was selective for the higher mass fraction of nominally 'non-absorbing' peptides. Considering the standardisation of enzyme to protein ratio during digestion, the total unique peptide count provided a measure of the relative proportion of distinct peptides surviving digestion due to both intrinsic protein-related and extrinsic process-related effects. As such, higher total counts of unique peptides were interpreted to reflect relative inhibition of enzymatic digestibility. In support, total peptide counts (Figure 4) followed the opposite relative trends to overall digestibility by OPA assay (Figure 3) indicating that the higher the OPA maximum (Figure 3c), the lower the total peptide count by MALDI-TOF-MS.

Total peptide counts were also expressed as proportions in different size ranges, providing an indication of the relative distribution of peptides of different sizes and stage of progression towards complete hydrolysis. Following in vitro digestion, it is unlikely that that there were any peptides $>3500 \mathrm{Da}$ and small peptides and FAAs would be $<700 \mathrm{Da}$ and undetectable by the MALDI-TOF-MS method. In general, the ratios of non-absorbing peptides in different size ranges for pasteurised milk and caseins were similar, indicating that digestibility of the caseins dominated the properties of total milk proteins following pasteurisation. In support of previous results, extensive digestion of whey proteins was evident under both infant and adult conditions, but either lack of petides $>2 \mathrm{kDa}$ (infant, Figure $4 \mathrm{a}$ ) or a high proportions of peptides $<1 \mathrm{kDa}$ (adult, Figure $4 \mathrm{~b}$ ). The relative proportions of peptides in the highest size range of $>2 \mathrm{kDa}$, were highest for SMP which most likely reflected the adverse effects of powder processing on protein digestibility. 
(a)

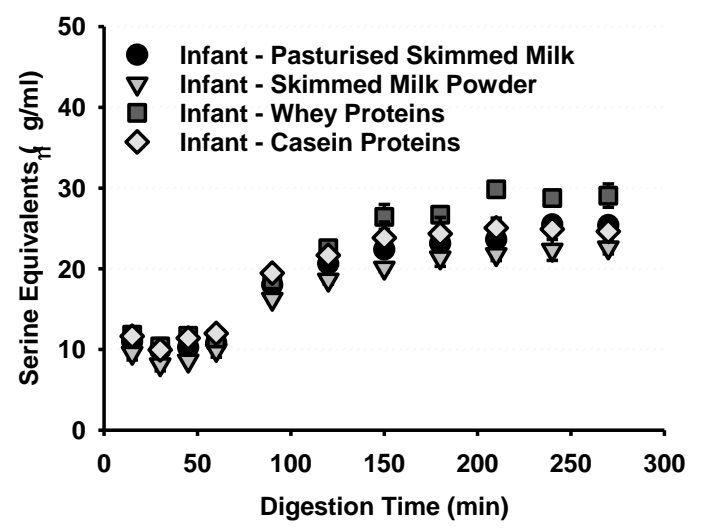

(b)

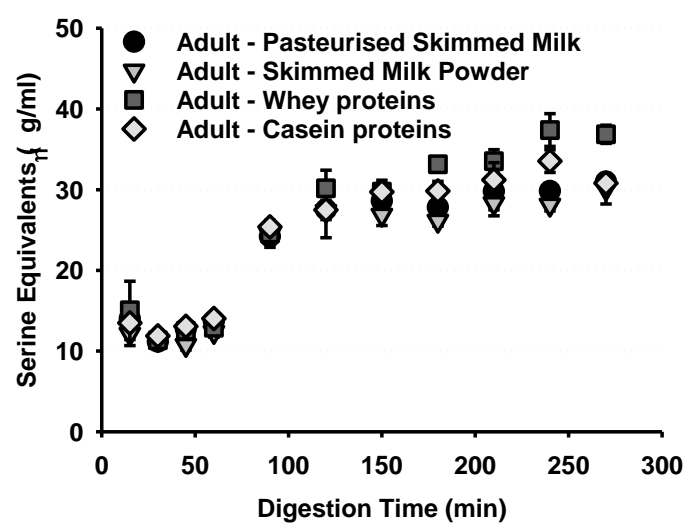

(c)

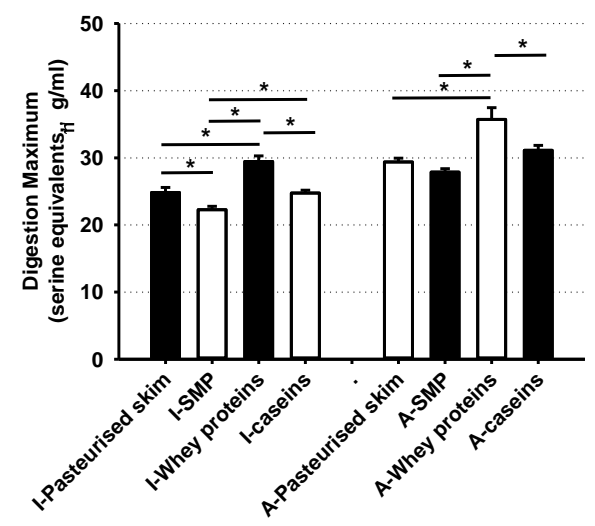

Figure 3. In vitro gastro-intestinal digestion profiles for pasteurised skimmed milk, skimmed milk powder, whey and casein proteins under (a) infant and (b) adult conditions, monitored by OPA assay. For infant conditions, predicted values of the maximum digestion (by Four Parameter Logistic Curve fitting) compared on a pairwise basis were all significantly different from each, other except for skim milk and caseinate $(p<0.05)$. For adult conditions, pairwise significant differences $(p<0.05)$ are shown

(a)

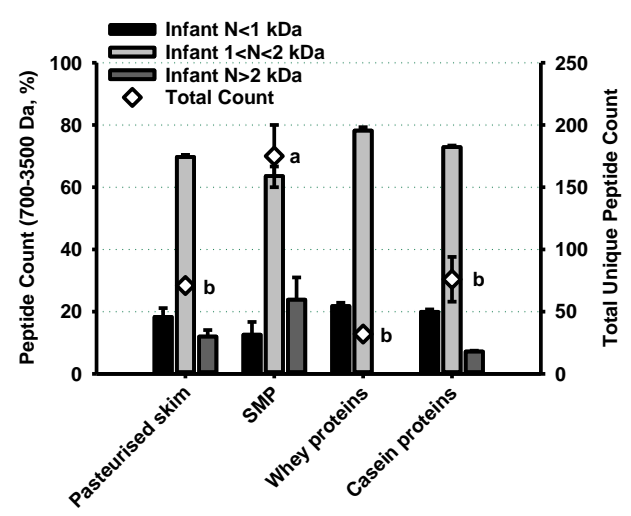

(b)

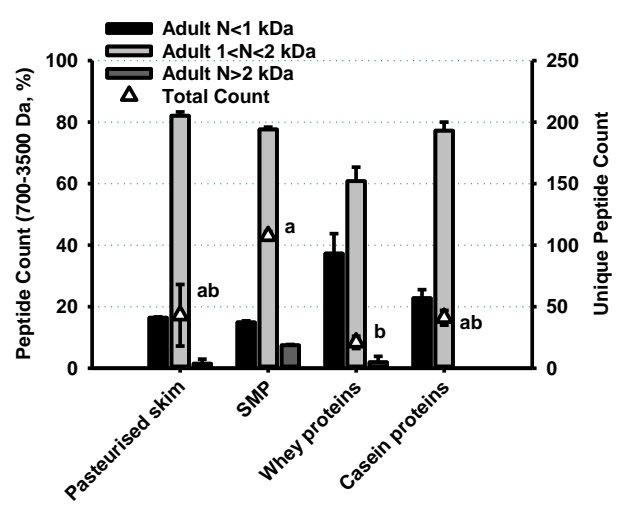

Figure 4. Analysis of final digestates from simulated gastro-intestinal digestion of: pasteurised skimmed milk, skimmed milk powder, whey and casein proteins, by MALDI-TOF-MS, under either (a) infant or (b) adult conditions, showing count of unique peptides in range 700-3500 Da and numbers in specific size ranges. Results

exclude undigested proteins and enzymes $>3500 \mathrm{Da}$. Data represent the mean and standard error (SE) of duplicates and significant differences $(p<0.05)$ by one-way ANOVA and Tukey test of multiple comparisons are indicated by different letters 


\section{Discussion}

\subsection{Milk Proteins are Incompletely Digested by Gastro-intestinal Enzymes in vitro}

The conditions in this work employed only gastric and duodenal stages of digestion while more elaborate methods can also include oral, including saliva (Kopf-Bolanz et al., 2012) and gut epithelial enterocyte brush border membrane (BBM) enzymes (Picariello et al., 2015) or supplementation of pancreatic enzymes with bile salts (Kopf-Bolanz et al., 2012; Picariello et al., 2015). While the use of salivatory enzymes and bile salts did not significantly influence the degree of hydrolysis (Kopf-Bolanz et al., 2012), BBM enzymes did significantly increase the degree of hydrolysis from $\sim 40$ to $70 \%$, in the absence of bile salts or $\sim 60$ to $\sim 70 \%$ with added bile salts (Picariello et al., 2015). This suggests that BBM enzymes play a significant role in conversion of peptides released by oral, stomach and duodenal digestive stages, into small peptides and amino acids necessary for absorption in the upper intestine. However, even after applying all digestive stages in sequence, the degree of hydrolysis was only $\sim 75 \%$ for a similar set of dairy samples (skimmed milk powder, whey protein isolate and caseinate (Picariello et al., 2015), to those studied here, signifying that these processed dairy products were resistant to complete digestion even by a more elaborate in vitro model of GI digestion. Therefore, although the in vitro digestion model does not necessarily predict the actual extent of digestion in vivo, the results are considered to indicate relative differences in protein digestibility of products tested.

Recent research efforts have focused on standardising research methodologies for simulating human digestion towards improving comparability of published data (Minekus et al., 2014). However, current methods of monitoring human digestion have limitations that can limit their interpretation and generalisability. PAGE-based methods are limited by (a) lack of attention to sample preparation and obscuring of physical and covalent cross-linked protein aggregation as an underlying factor regulating digestibility, (b) lack of detection of high mass aggregates that are not separated by PAGE and (c) lack of detection of peptides and free amino acids < 3-4 kDa (Dupont, Mandalari, Molle, Jardin, Rolet-Repecaud, et al., 2010). Likewise, MS-based methods are also biased towards peptides of 5-30 amino acids and some ionisation techniques cause peptide fragmentation that cannot be differentiated from digestive hydrolysis (Kopf-Bolanz et al., 2012). In the methods applied in this research, digestive hydrolysis of proteins was characterised by complimentary methods capturing (a) total hydrolysis by OPA derivatisation, (b) the relative distribution of mid-range peptides (700 to $3500 \mathrm{Da}$ ) and (c) chromatographic detection of total free amino acids in the digestate supernatant. Results indicated that under the experimental digestion conditions, and suite of analytical methods, the dairy products tested were not completely digested into free amino acids (Figures 2 and 4), in contradiction to the conclusion drawn on casein digestibility under infant conditions based on SDS-PAGE monitoring (Dupont, Mandalari, Molle, Jardin, Leonil, et al., 2010).

The results collectively allow comparison of changes in digestibility related to either protein type or processing treatments. Variations in digestibility of processed dairy products have been previously reported and associated with loss of protein solubility in the case of infant formulae products (Rudloff \& Lonnerdal, 1992), with variable degrees of milk protein denaturation and aggregation (Singh \& Creamer, 1991; Williams et al., 2008) and loss of lysine reactivity to OPA due to Maillard chemical processes (Morales, Romero, \& JimenezPerez, 1996; Vigo, Malec, Gomez, \& Llosa, 1992).

\subsection{Milk Proteins are Digested Differently under Infant Versus Adult Conditions}

The previous results demonstrated that, compared with adult conditions, infant digestion of milk proteins was consistently relatively less efficient. Infant digestive capacity is lower than adult capacity partly reflecting the higher $\mathrm{pH}$ and lower levels of pepsin in the stomach (Bourlieu et al., 2014). However, although proteolysis was relatively limited in the gastric phase (0-90 min, Figures 1a, 3), exposure to pepsin was important for subsequent intestinal digestion efficiency. For example, the complimentary activity of pepsin and chyomotrypsin was demonstrated for in vitro digestion of $\alpha \mathrm{La}$, where exhaustion of digestive sites was observed at gastric $\mathrm{pH}$ but further digestion of $\alpha$ La was evident under duodenal conditions (Levi \& Lesmes, 2014).

Differences in digestive efficacy in gastric conditions between whey and casein proteins were also apparent, with relatively lower digestion efficiency for whey proteins (lower values of serine equivalents from 0-90 mins, Figure 3). In support, digestion rates were significantly lower at $\mathrm{pH} 3.0$ versus 2.5 for $\alpha$-lactalbumin $(\alpha \mathrm{La})$ and $\beta$-lactoglobulin ( $\beta \mathrm{Lg}$ ) but not significantly different for casein (Sakai et al., 2000). Studies of digestion of (unpasteurised) human milk compared with milk recovered in the gastric aspirate of a baby, indicated that at this digestion stage, casein was significantly more digestible than whey proteins particularly $\alpha \mathrm{La}$ and lactoferrin (Chatterton, Rasmussen, Heegaard, Sorensen, \& Petersen, 2004), possibly suggesting caseins versus whey protein fractions are intended for immediate versus delayed amino acid nutrient supply, respectively. However, the trend favouring higher digestibility of caseins was reversed in piglets fed infant formula comprising native 
whey proteins combined with thermally-processed skimmed milk powder (SMP) to balance the whey-casein ratio, and which clearly showed significant digestive-resistance of thermally processed caseins versus native whey proteins at the ileum (Bouzerzour et al., 2012). Importantly, in claims about the relatively fast versus slow absorption and signalling behaviours of whey versus casein proteins, respectively, which are known to reflect relative digestibility, the processing state of dairy proteins is rarely considered (Bendtsen, Lorenzen, Bendsen, Rasmussen, \& Astrup, 2013).

It is possible that inefficient conditions of infant digestion may actually be designed to divert a proportion of non-absorbing protein towards the lower intestine to stimulate of colonisation of the microbiota. Alternatively, digestion-resistant domains of whey proteins (Picariello et al., 2015) may also permit supply of bioactive peptides (Chatterton et al., 2004), acting both within the lumen, at luminal gut receptors and post-absorption (Hernandez-Ledesma et al., 2014).

\subsection{Undigested Polypeptides have Potential for Bioactive Function}

The present study demonstrated that processed forms of milk proteins displayed relatively lower digestibility under both infant and adult conditions and likely favoured survival of undigested or aggregated forms of proteins. Alternatively, the recovery of persistent, undigested peptides from casein and whey proteins (Dupont, Mandalari, Molle, Jardin, Rolet-Repecaud, et al., 2010; Picariello et al., 2015) particularly under infant digestive conditions (Dallas et al., 2014), may represent an intended digestive feature of 'milk', providing specific bioactive functions to benefit the neonate (or calf).

Bioactive peptides are known to be released by digestive and other enzymes, although evidence of outcomes for infant development and health of non-infant consumers is limited (Hernandez-Ledesma et al., 2014). Even a comprehensive in vitro digestion model, including oral, peptic, pancreatic and BBM enzymes applied to milk proteins achieved only $71-77 \%$ degree of hydrolysis and indicated that persistent groups of peptides survived digestion (Picariello et al., 2015). While, these unabsorbed peptides may be available for intestinal bacteria, in the case of milk proteins, which represent an exclusive neonatal food, they may also be intended for exerting specific bioactive functions. For example, fragments of $\beta$-casein $(\beta C n, 60-66,94-123)$ which survived in vitro digestion (Picariello et al., 2015) were reported to induce protective mucin secretion in the jejunum (Hernandez-Ledesma et al., 2014). Likewise, digestion-resistant peptides released from $\alpha \mathrm{S} 1-\mathrm{Cn}(1-23 ; 30-38$ and others, (Picariello et al., 2015) were reported for their anti-bacterial and immunomodulatory properties (Hernandez-Ledesma et al., 2014). In support, undigested peptides recovered from the ileum of piglets fed infant formula, including $\beta \mathrm{Cn}$ (74-86) and $\beta \mathrm{Lg}(1-40,102-124)$, overlapped with those surviving in vitro simulated digestion (Picariello et al., 2015).

It is possible that only digestion-resistant bioactive peptides can elicit measurable activity following oral intake and this might explain the inconsistent clinical efficacy reported for dairy peptides with demonstrated in vitro bioactivities (Nongonierma \& FitzGerald, 2015). However, the present study suggests that differences in digestive-resistance might be expected between adults and infants, with much greater survival of undigested peptides under infant digestion conditions (Dallas et al., 2014), exerting altered bioactivities compared with breast milk and also potentially greater risk of immunogenicity (Dupont, Mandalari, Molle, Jardin, Rolet-Repecaud, et al., 2010).

\subsection{Undigested Peptides Undergo Colonic Fermentation and Absorption}

The simple in vitro digestive model adopted here including gastro-intestinal (GI) enzymes simulated upper intestinal stages of dietary protein proteolysis. It is likely that efficient early proteolysis maximises efficiency of subsequent luminal digestive processes involving both luminal bacteria and BBM proteases (Davila et al., 2013) and maximises upper GI absorption (Ten Have et al., 2007). Conversely, survival of higher mass peptides and compromised pre-ileal digestibility therefore favours displacement into the colon. Proportions of ileal $\mathrm{N}$ losses were greater for soy versus milk protein in human subjects supporting that protein quality and inherent digestibility also influences pre-ileal absorption (Gaudichon et al., 2002). By extension, inefficient luminal digestion and absorption of protein favours supply to the colonic microbiota with greater chance for conversion into harmful metabolites, particularly arising from sulphur-containing and aromatic amino acids (Davila et al., 2013). This research provides an indication of the relative proportions of 'non-absorbing' peptides produced by in vitro enzymatic digestion, with potential to either exert bioactive, including immunogenic effects, and/or to supply substrates for microbial fermentation.

The distribution and utilisation of dietary $\mathrm{N}$ between the host (for host protein synthesis and turnover) and the microbiota (for biomass and turnover) is a key question in order to understand the precise intake requirements of dietary protein and ratios of amino acids, necessary for human health. It is understood that the collective 
exogenous and endogenous protein, peptide and amino acid content versus bacterial load of the upper intestine are relatively high and low, respectively and this ratio is amplified along the colon (Davila et al., 2013). In support, a comparison of digestibilities of fermented, hydrolysed and standard infant formulae in piglets demonstrated that the least digestible standard formula was associated with significantly higher ileal digesta mass (slower transit to maximise digestion) and $>2$-fold higher total proteolytic activity, demonstrating costly physiological responses needed to digest and absorb lower quality protein (Abrahamse et al., 2015). Furthermore, the responses of the colonic microbiota to an increase in supply of undigested dietary protein caused adverse disturbance of microbiota, short chain fatty acid production and to putrefaction of the distal colon (Davila et al., 2013).

The present study demonstrates that thermal processing of milk proteins compromises in vitro gastro-intestinal enzymatic digestion and potentially accounts for an increase in supply of undigested protein to the colon. This supports the hypothesis that under adequate protein intakes, luminal absorption of dietary protein favours amino acid supply to the host and ileal protein loss preferentially supplies the colonic microbiota, with unknown long-term consequences for health.

\section{Conclusion}

This research demonstrates that complimentary methods of characterisation are required to account for the size distributions of digestates of milk proteins, which can inform understanding of the absorption properties of processed forms of milk. The present study involved a simple model of in vitro gastro-intestinal enzymatic digestion adjusted for infant and adult conditions. Collectively, OPA digestion profiles and characterisation of digestates by MALDI-MS and SEC methods confirmed that, processed forms of milk proteins produced divergent effects on digestibility. Undigested proteins may elicit bioactivities including immunogenic responses and are likely to undergo transfer to the colon and be subjected to fermentative digestive processes. While a proportion of endogenous protein loss from the ileum is considered normal for $\mathrm{N}$ supply to the microbiota, excessive displacement of undigested proteins to the colon, increases the opportunity for producing toxic metabolites of amino acids and in extreme cases, to putrefaction. Applications of the research methods described will inform development of processing approaches to optimise digestibility of dairy proteins and explore consequences for consumer health.

\section{References}

Abrahamse, E., Huybers, S., Alles, M. S., Renes, I. B., Knol, J., Bouritius, H., \& Ludwig, T. (2015). Fermented Infant Formula Increases Ileal Protein Digestibility and Reduces Ileal Proteolytic Activity Compared with Standard and Hydrolyzed Infant Formulas in Piglets. Journal of Nutrition, 145(7), 1423-1428. https://doi.org/10.3945/jn.114.208314

Bendtsen, L. Q., Lorenzen, J. K., Bendsen, N. T., Rasmussen, C., \& Astrup, A. (2013). Effect of Dairy Proteins on Appetite, Energy Expenditure, Body Weight, and Composition: a Review of the Evidence from Controlled Clinical Trials. Advances in Nutrition, 4(4), 418-438. https://doi.org/10.3945/an.113.003723

Bourlieu, C., Menard, O., Bouzerzour, K., Mandalari, G., Macierzanka, A., Mackie, A. R., \& Dupont, D. (2014). Specificity of Infant Digestive Conditions: Some Clues for Developing Relevant In Vitro Models. Critical Reviews in Food Science and Nutrition, 54(11), 1427-1457. https://doi.org/10.1080/10408398.2011.640757

Bouzerzour, K., Morgan, F., Cuinet, I., Bonhomme, C., Jardin, J., Le Huerou-Luron, I., \& Dupont, D. (2012). In vivo digestion of infant formula in piglets: protein digestion kinetics and release of bioactive peptides. British Journal of Nutrition, 108(12), 2105-2114. https://doi.org/10.1017/s000711451200027x

Chatterton, D. E. W., Rasmussen, J. T., Heegaard, C. W., Sorensen, E. S., \& Petersen, T. E. (2004). In vitro digestion of novel milk protein ingredients for use in infant formulas: Research on biological functions. Trends in Food Science \& Technology, 15(7-8), 373-383. https://doi.org/10.1016/j.tifs.2003.12.004

Dallas, D. C., Guerrero, A., Khaldi, N., Borghese, R., Bhandari, A., Underwood, M. A., . . Barile, D. (2014). A Peptidomic Analysis of Human Milk Digestion in the Infant Stomach Reveals Protein-Specific Degradation Patterns. Journal of Nutrition, 144(6), 815-820. https://doi.org/10.3945/jn.113.185793

Davila, A. M., Blachier, F., Gotteland, M., Andriamihaja, M., Benetti, P. H., Sanz, Y., \& Tome, D. (2013). Intestinal luminal nitrogen metabolism: Role of the gut microbiota and consequences for the host (Reprinted from Pharmacological Research vol 68, pg 95-107, 2012). Pharmacological Research, 69(1), 114-126. https://doi.org/10.1016/j.phrs.2013.01.003

Dupont, D., Mandalari, G., Molle, D., Jardin, J., Leonil, J., Faulks, R. M., ... Mackie, A. R. (2010). Comparative 
resistance of food proteins to adult and infant in vitro digestion models. Molecular Nutrition \& Food Research, 54(6), 767-780. https://doi.org/10.1002/mnfr.200900142

Dupont, D., Mandalari, G., Molle, D., Jardin, J., Rolet-Repecaud, O., Duboz, G., ... Mackie, A. R. (2010). Food processing increases casein resistance to simulated infant digestion. Molecular Nutrition \& Food Research, 54(11), 1677-1689. https://doi.org/10.1002/mnfr.200900582

Fan, P. X., Li, L. S., Rezaei, A., Eslamfam, S., Che, D. S., \& Ma, X. (2015). Metabolites of Dietary Protein and Peptides by Intestinal Microbes and their Impacts on Gut. Current Protein \& Peptide Science, 16(7), 646-654. https://doi.org/10.2174/1389203716666150630133657

Fuller, M. (2012). Determination of protein and amino acid digestibility in foods including implications of gut microbial amino acid synthesis. British Journal of Nutrition, 108, S238-S246. https://doi.org/10.1017/s0007114512002279

Gaudichon, C., Bos, C., Morens, C., Petzke, K. J., Mariotti, F., Everwand, J., ... Metges, C. C. (2002). Ileal losses of nitrogen and amino acids in humans and their importance to the assessment of amino acid requirements. Gastroenterology, 123(1), 50-59. https://doi.org/10.1053/gast.2002.34233

Hernandez-Ledesma, B., Garcia-Nebot, M. J., Fernandez-Tome, S., Amigo, L., \& Recio, I. (2014). Dairy protein hydrolysates: Peptides for health benefits. International Dairy Journal, 38(2), 82-100. https://doi.org/10.1016/j.idairyj.2013.11.004

Hozyasz, K. K., \& Slowik, M. (2013). Alternatives to standard cow milk: pros and cons. Przeglad Gastroenterologiczny, 8(2), 98-107. https://doi.org/10.5114/pg.2013.34835

Kopf-Bolanz, K. A., Schwander, F., Gijs, M., Vergeres, G., Portmann, R., \& Egger, L. (2012). Validation of an In Vitro Digestive System for Studying Macronutrient Decomposition in Humans. Journal of Nutrition, 142(2), 245-250. https://doi.org/10.3945/jn.111.148635

Lacroix, M., Bon, C., Bos, C., Leonil, J., Benamouzig, R., Luengo, C., ... Gaudichon, C. (2008). Ultra High Temperature Treatment, but Not Pasteurization, Affects the Postprandial Kinetics of Milk Proteins in Humans. Journal of Nutrition, 138(12), 2342-2347. https://doi.org/10.3945/jn.108.096990

Levi, C. S., \& Lesmes, U. (2014). Bi-compartmental elderly or adult dynamic digestion models applied to interrogate protein digestibility. Food \& Function, 5(10), 2402-2409. https://doi.org/10.1039/c4fo00478g

Lindberg, T., Borulf, S., \& Jakobsson, I. (1989). Digestion of milk-proteins in infancy Acta Paediatrica Scandinavica, 29-33.

Maubois, J. L., \& Lorient, D. (2016). Dairy proteins and soy proteins in infant foods nitrogen-to-protein conversion factors. Dairy Science \& Technology, 96(1), 15-25. https://doi.org/10.1007/s13594-015-0271-0

Menard, O., Cattenoz, T., Guillemin, H., Souchon, I., Deglaire, A., Dupont, D., \& Picque, D. (2014). Validation of a new in vitro dynamic system to simulate infant digestion. Food Chemistry, 145, 1039-1045. https://doi.org/10.1016/j.foodchem.2013.09.036

Minekus, M., Alminger, M., Alvito, P., Ballance, S., Bohn, T., Bourlieu, C., ... Brodkorb, A. (2014). A standardised static in vitro digestion method suitable for food - an international consensus. Food \& Function, 5(6), 1113-1124. https://doi.org/10.1039/c3fo60702j

Morales, F. J., Romero, C., \& JimenezPerez, S. (1996). Evaluation of heat-induced changes in Spanish commercial milk: Hydroxymethylfurfural and available lysine content. International Journal of Food Science and Technology, 31(5), 411-418. https://doi.org/10.1046/j.1365-2621.1996.00357.x

Morowitz, M. J., Carlisle, E. M., \& Alverdy, J. C. (2011). Contributions of Intestinal Bacteria to Nutrition and Metabolism in the Critically Ill. Surgical Clinics of North America, 91(4), 771-785. https://doi.org/10.1016/j.suc.2011.05.001

Nongonierma, A. B., \& FitzGerald, R. J. (2015). The scientific evidence for the role of milk protein-derived bioactive peptides in humans: A Review. Journal of Functional Foods, 17, 640-656. https://doi.org/10.1016/j.jff.2015.06.021

Picariello, G., Miralles, B., Mamone, G., Sanchez-Rivera, L., Recio, I., Addeo, F., \& Ferranti, P. (2015). Role of intestinal brush border peptidases in the simulated digestion of milk proteins. Molecular Nutrition \& Food Research, 59(5), 948-956. https://doi.org/10.1002/mnfr.201400856

Rudloff, S., \& Lonnerdal, B. (1992). Solubility and digestibility of milk-proteins in infant formulas exposed to 
different heat-treatments Journal of Pediatric Gastroenterology and Nutrition, 15(1), 25-33. https://doi.org/10.1097/00005176-199207000-00005

Sakai, K., Yoshino, K., Satter, M. A., Ota, F., Nii, Y., Fukuta, K., ... Yamamoto, S. (2000). Effects of pH variation and $\mathrm{NaCl}$ on in vitro digestibility of cow's milk proteins in commercially available infant formulas. Journal of Nutritional Science and Vitaminology, 46(6), 325-328.

Seiquer, I., Delgado-Andrade, C., Haro, A., \& Navarro, M. P. (2010). Assessing the effects of severe heat treatment of milk on calcium bioavailability: In vitro and in vivo studies. Journal of Dairy Science, 93(12), 5635-5643. https://doi.org/10.3168/jds.2010-3469

Singh, H., \& Creamer, L. K. (1991). Denaturation, aggregation and heat-stability of milk protein during the manufacture of skim milk powder Journal of Dairy Research, 58(3), 269-283.

Ten Have, G. A. M., Engelen, M., Lulking, Y. C., \& Deutz, N. E. P. (2007). Absorption kinetics of amino acids, peptides, and intact proteins. International Journal of Sport Nutrition and Exercise Metabolism, 17, S23-S36.

Vigo, M. S., Malec, L. S., Gomez, R. G., \& Llosa, R. A. (1992). Spectrophotometric assay using ortho-pthaldialdehyde for determination of reactive lysine in dairy products. Food Chemistry, 44(5), 363-365. https://doi.org/10.1016/0308-8146(92)90269-8

Wijayanti, H. B., Bansal, N., \& Deeth, H. C. (2014). Stability of Whey Proteins during Thermal Processing: A Review. Comprehensive Reviews in Food Science and Food Safety, 13(6), 1235-1251. https://doi.org/10.1111/1541-4337.12105

Williams, R. P. W., D'Ath, L., \& Zisu, B. (2008). Role of protein aggregation in heat-induced heat stability during milk powder manufacture. Dairy Science \& Technology, 88(1), 121-147. https://doi.org/10.1051/dst:2007048

Wu, T., Taylor, C., Nebl, T., Ng, K., \& Bennett, L. E. (2017). Effects of chemical composition and baking on in vitro digestibility of proteins in breads made from selected gluten-containing and gluten-free flours. Food Chemistry, 233, 514-524. https://doi.org/10.1016/j.foodchem.2017.04.158

Zhou, S. J., Sullivan, T., Gibson, R. A., Lonnerdal, B., Prosser, C. G., Lowry, D. J., \& Makrides, M. (2014). Nutritional adequacy of goat milk infant formulas for term infants: a double-blind randomised controlled trial. British Journal of Nutrition, 111(9), 1641-1651. https://doi.org/10.1017/s0007114513004212

\section{Copyrights}

Copyright for this article is retained by the author(s), with first publication rights granted to the journal.

This is an open-access article distributed under the terms and conditions of the Creative Commons Attribution license (http://creativecommons.org/licenses/by/4.0/). 